\title{
Clinical Characteristics and Outcomes of COVID-19 Positive Acute Coronary Syndrome Patients; a multisource Electronic Healthcare Records Study from England
}

Short running title: Outcomes of COVID-19 ACS patients.

Muhammad Rashid $\mathrm{PhD}^{1,2}$, Jianhua $\mathrm{Wu} \mathrm{PhD}^{3}$, Adam Timmis $\mathrm{MD}^{4}$, Nick Curzen $\mathrm{PhD}^{5}$, Sarah Clarke ${ }^{6}$, Azfar Zaman $\mathrm{PhD}^{7}$, James Nolan ${ }^{1,2}$, Ahmad Shoaib MD ${ }^{1,2}$, Mohamed O Mohamed $\mathrm{MBChB}^{1}$, Mark A de Belder $\mathrm{MD}^{8}$, John Deanfield FRCP ${ }^{9}$, Chris P Gale $\mathrm{PhD}^{3,10,11,}$, Mamas A. Mamas DPhil ${ }^{1,2,12}$

1. Keele Cardiovascular Research Group, Institute for Prognosis Research, School of Primary Care, Keele University

2. Department of Cardiology, Royal Stoke Hospital, Stoke-on-Trent, UK

3. Leeds Institute for Data Analytics, University of Leeds, Leeds, UK

4. Queen Mary University London, UK

5. Coronary Research Group, University Hospital Southampton \& Faculty of Medicine, University of Southampton, UK

6. Department of Cardiology, Royal Papworth Hospital, Cambridge, UK

7. Department of Cardiology, Freemen Hospital, Newcastle Upon Tyne, UK

8. National Institute for Cardiovascular Outcomes Research, Barts Health NHS Trust, London, UK

9. Institute of Cardiovascular Sciences, University College London, London, UK

10. Leeds Teaching Hospitals NHS Trust, Leeds, UK

11. Leeds Institute of Cardiovascular and Metabolic Medicine.

12. Department of Medicine, Thomas Jefferson University, Philadelphia, Pennsylvania 
Background: Patients with underlying cardiovascular disease and Coronavirus disease 2019 (COVID-19) infection are at increased risk of morbidity and mortality. However, there is limited information on management and outcomes of patients presenting with acute coronary syndrome (ACS) and concomitant COVID19 infection.

Objectives: This multisource national analysis of live data from England was designed to characterise the presenting profile and outcomes of patients hospitalized with ACS and COVID-19 infection.

Methods: Multisource data from all acute NHS hospital in England was linked to study the characteristics and outcomes of patients hospitalized with COVID-19 ACS compared to non COVID-19 ACS patients. Hierarchical multilevel models were constructed to study the association between COVID19 ACS and in-hospital and 30-day mortality.

Results: Between 1st March 2020 and 31st May 2020, 517 (4.0\%) were admitted with COVID- 19 ACS from a total of 12,958 ACS patients. COVID-19 ACS patients were generally older, BAME ethnicity, more comorbid and had unfavourable presenting characteristics compared to non-COVID-19 ACS patients. They were less likely to receive invasive coronary strategy in the form of coronary angiography $(67.7 \%$ vs $81.0 \%)$, PCI (30.2\% vs $53.9 \%$ ), dual antiplatelet medication $76.3 \%$ vs $88.0 \%$ ), and other important secondary medication. Patients with COVID-19 ACS had higher in-hospital (aOR 3.27 95\%CI 2.41-4.42) and 30-day mortality (aOR 6.53 95\%CI 5.1-8.36) compared to non COVID-19 ACS group.

Conclusion: COVID-19 infection is prevalent but less frequent in the patients hospitalized with ACS in England. Presence of COVID-19 infection in patients with ACS is associated with significant mortality hazard. 


\section{Introduction:}

Coronavirus disease 2019 (COVID-19), caused by severe acute respiratory syndrome coronavirus-2 (SARS-CoV-2), has affected more than 17 million people resulting in almost 700,000 deaths worldwide ${ }^{1}$. Although, COVID-19 patients predominantly present with respiratory symptoms, various extra-pulmonary manifestations including thrombotic events, myocardial injury and ischaemia, acute kidney injury and cardiac arrhythmias have also been reported $^{2,3}$.

Acute coronary syndrome (ACS) in the context of viral infection may be related to atherosclerotic plaque rupture precipitated by endothelial cell damage, a cytokine storm and a heightened inflammatory state ${ }^{4}$ Furthermore, admission with an ACS during the COVID-19 pandemic in which large numbers of patients were hospitalised with COVID-19, may increase the risk of nosocomial transmission of COVID-19 in this vulnerable patient group.

The management of patients presenting with suspected ACS in the context of COVID19 remains a challenge ${ }^{7}$. There are limited data regarding the clinical characteristics, management strategies and post-discharge mortality of patients hospitalized with a diagnosis of ACS and concomitant COVID-19 infection ${ }^{7}$. Small case series of 18 and 28 patients presenting with ST-elevation acute myocardial infarction (STEMI) and concomitant COVID19 infection have reported significant variability in presenting characteristics and in-hospital survival of these patients ${ }^{8,9}$. These reports lacked data around clinical presentation, pharmacological treatments and post-discharge survival. Fewer data are available from a national, or from a broader ACS perspective including non-ST-elevation myocardial infraction (NSTEMI). Such information could prove useful in order to devise optimal pathways of care in the event of a second wave of COVID-19. 
This study, using high resolution, multisource contemporary national data from England, systematically profiles the presenting and procedural characteristics, in-hospital and 30-day mortality in patients admitted with a suspected diagnosis of ACS and concomitant COVID-19 infection. The primary aim was to investigate the in-hospital and 30-day all-cause mortality in patients hospitalized with COVID-19 ACS diagnosis compared with those without COVID-19 ACS. The second aim was to describe the differences in management and independent predictors of 30-day mortality of those with COVID-19 ACS.

\section{Methods}

Study data

An unselected, real-world cohort of all patients hospitalized with a suspected diagnosis of ACS in England was derived by linking patient records across four different sources of data, namely Hospital Episode Statistics (HES), the Myocardial Ischaemia National Audit Project (MINAP), the British Cardiovascular Intervention Society (BCIS) percutaneous coronary intervention registry and Civil Registration Death data. The full details about the validity, strengths, limitations and utility for research purposes have been described previously ${ }^{10-12}$. Briefly, HES contains International Statistical Classification of Disease-10 ${ }^{\text {th }}$ Revision (ICD10) clinical, geographic, administrative and patient information of all patients hospitalized in any National Health Service (NHS) hospital in England ${ }^{10}$. MINAP is an exclusive ACS registry designed to collect information across 130 data fields about patient demographics, use of various pharmacological and invasive treatments and in-hospital care of patients hospitalized with a suspected diagnosis of ACS (type 1 myocardial infarction) in any NHS acute care hospital in England ${ }^{12}$. Similarly, almost over $98 \%$ of the PCI activity in England is captured in the BCIS PCI registry, which is designed to collect detailed procedural and clinical data of all patients undergoing $\mathrm{PCI}^{11}$. Finally, the civil registration of death register 
holds the mortality information of all deaths in England. All patient records in these datasets can be identified using a unique 10-digit number. For the purposes of this study we used live reporting data from all hospitals in England submitting their data to these respective registries during the COVID-19 pandemic.

\section{Ethical approval}

This study was conducted under the endorsement of the Chief Scientific Advisor to the UK government and Scientific Advisory Group for Emergencies (SAGE). The access to the data was granted under the Health and Social Care State Secretary's notice issued under Regulation 3(4) of the NHS (Control of Patient Information Regulations) 2002 (COPI) to NHS Digital, allowing NHS Digital to share confidential patient information with organisations entitled to process this under COPI for COVID-19 purposes. Furthermore, MINAP and BCIS data are collected and hosted by the National Institute of Cardiovascular Research (NICOR) and used for audit and research purposes without formal individual patient consent under section 251 of the NHS Act $2006^{13-16}$. The study complies with the Declaration of Helsinki.

\section{Study cohort}

The analytical cohort for this study consisted of consecutive patients aged $\geq 18$ years hospitalized with a suspected diagnosis of ACS in England and documented within the MINAP registry, between $1^{\text {st }}$ March 2020 to $31^{\text {st }}$ May 2020. The COVID-19 status information for all patients was derived from HES using ICD-10 codes 'U071' (confirmed) and 'U072' (suspected) and linked with the MINAP record of the same patient matching across the two datasets based on their unique NHS number and admission date. In the second step, the records of all these patients were linked across to the records in the BCIS PCI registry using the same NHS number and admission week. Finally, the mortality information 
of all patients was tracked within 30 days beyond discharge or up to $10^{\text {th }}$ July 2020 from the Civil registration of Death register. Supplementary figure 1 illustrates the cohort selection and data linkage steps of all patients in the study.

Final study data contained comprehensive detailed information about patient demographics, COVID-19 status, clinical characteristics, comorbidities, pre-hospital and in-hospital pharmacological treatments, cardiac investigations, invasive coronary procedures, procedural characteristics and complications. Patients with missing or invalid NHS number and date of admission were excluded from the analysis. Patients with valid diagnosis codes of COVID-19 captured in the HES data were defined as the "COVID-19 ACS" group whilst all other ACS patients were defined as the "non COVID-19 ACS" group. Time to reperfusion therapy for STEMI was calculated from time of admission to time of receipt of reperfusion treatment where time of admission was defined as time of arrival into hospital. The primary outcomes of interest were in-hospital and 30-day mortality in 'COVID-19 ACS' compared with 'non COVID-19 ACS' patients.

\section{Statistical analysis}

Baseline characteristics were reported as number and percentages for categorical variables, means with standard deviation or median with interquartile ranges for continuous data. Statistical differences between the two groups were obtained using Chi-Square test or t-test or Kruskal-Wallis tests as appropriate. The daily counts of COVID-19 positive ACS patients were presented using a simple daily moving average from 1st March 2020 up to and including $31^{\text {st }}$ May 2020, adjusted for seasonality. Multiple imputations using chained equation (MICE) techniques were used to impute missing values in all the study variables. Each of the imputation models included all the other variables used in the analyses as reported in the online supplement (Supplementary Table 1). Linear regression for continuous 
variables, multinomial for nominal variables, ordinal logistic regression for ordered factors and logistic regression models for binary variables were used to generate 10 imputed datasets and all subsequent analyses were performed on these and results were pooled using Robin's rule $^{17,18}$

To study the association between 'COVID-19 ACS' status and clinical outcomes, hierarchical logistic regression models with random intercept were constructed. The hospital ID was used as a random intercept to account for nesting of patients within the different hospitals. All models were adjusted for age, sex, ethnicity, body mass index, presenting characteristic (blood pressure, heart rate, cardiac arrest, clinical syndrome, creatinine, Kilip class, left ventricular systolic function), cardiovascular comorbidities (previous PCI, previous CABG, previous AMI, previous cerebrovascular event, peripheral vascular disease, renal dysfunction, heart failure, hypercholesterolemia, angina, diabetes, smoking status, asthma or chronic obstructive airway disease and family history of coronary heart disease), in-hospital pharmacology (low molecular weight heparin, unfractionated heparin, warfarin, loop diuretic, glycoprotein IIb/IIIa inhibitor), discharge pharmacology (dual antiplatelet medication use, statin, angiotensin converting enzyme (ACE) or angiotensin receptor blocker use), receipt of coronary angiography or PCI and cardiology care. For patients undergoing PCI, the association between 'COVID-19 ACS' status and mortality was estimated by constructing separate models adjusting all the procedural information reported in table 3 and in addition to the aforementioned confounders. The independent predictors of 30-day mortality were studied using multivariable logistic regression model. All tests were two-sided and statistical significance considered as $\mathrm{P}<0.05$. Statistical analyses were performed in Stata MP 16.0 College station, Texas, US via secure remote access on the NHS Digital servers hosting all the datasets.

\section{Results:}


Between $1^{\text {st }}$ March and $31^{\text {st }}$ May 2020, 12,958 patients were hospitalized with ACS in England, of which 517 (4.0\%) were COVID-19 positive. There was a steady increase in the number of daily COVID-19 ACS hospitalizations during March, reaching a peak in the first week of April followed by a steady decline by the end of May (Figure 1). Higher proportions of daily COVID-19 ACS cases were admitted with a suspected NSTEMI compared to STEMI throughout the study period.

\section{Patient characteristics}

Patients in the COVID-19 ACS group were older compared with the non COVID-19 ACS group (72.8 year vs 67.0 year), and a greater proportion were from Black, Asian and Ethnic minority origin (20.2\% vs $12.8 \%$ ), they had a lower body mass index (26.9 vs 28.2$)$ and more likely to be hospitalized with NSTEMI (67.0\% vs 62.0\%). The COVID-19 ACS group also exhibited an increased incidence of in-hospital cardiac arrest (6.3\% vs 3.0\%), higher troponin levels, and were more likely to have presented in pulmonary oedema (9.0\% vs $3.4 \%)$ or cardiogenic shock (9.6\% vs $3.9 \%)$. They had a higher prevalence of heart failure $(23.7 \%$ vs $13.4 \%)$, cerebrovascular disease $(15.7 \%$ vs $8.0 \%)$, insulin treated diabetes (13.6\% vs $7.5 \%$ ) and hypertension $(69.4 \%$ vs $58.3 \%)$.

Out of 12,958 patients, $6,864(53.0 \%)$ underwent PCI and were successfully linked from MINAP into the BCIS registry (supplementary figure 1). COVID-19 ACS patients undergoing PCI were of similar age and had similar baseline characteristics to the overall ACS cohort (Table 2). The angiographic and procedural profiles of COVID-19 ACS patients (such as number of lesions attempted, vessels attempted, multivessel PCI, number of stents used, use of intracoronary imaging such as IVUS, OCT and pressure wire use) were similar to the non COVID-19 ACS cohort undergoing PCI. From the patients who didn't receive 
PCI, the proportions of angiographically normal coronaries or surgical disease were similar in both non COVID-19 and COVID-19 ACS groups.

\section{Discharge medication and Guidelines-indicated care}

Patients in the COVID-19 ACS group were less likely to receive optimal secondary prevention medication such as aspirin (90.5\% vs $94.5 \%)$, dual anti-platelet medications (76.3\% vs $88.0 \%)$, statin (89.1\% vs $95.1 \%)$ and ACE/ARB (80.4\% vs $88.6 \%)$ therapy compared with the non COVID-19 ACS group. Overall, only one third (30.2\% vs 53.9\%) of COVID-19 ACS patients received PCI compared to non COVID-19 ACS patients. COVID19 NSTEMI patients were also less likely to undergo invasive coronary angiography $(67.7 \%$ vs $81.0 \%)$ and PCI (22.2\% vs $46.0 \%)$ compared to the non COVID-19 NSTEMI cohort.

The median time from in-hospital arrival to reperfusion for patients presenting with STEMI was 13.2 minutes longer in the COVID-19 STEMI group compared with the non COVID-19 STEMI group. COVID-19 NSTEMI group also experienced delays in time to coronary angiography (38.1 hours vs 33.7 hours) compared with non COVID-19 NSTEMI group. Less than half of the COVID-19 ACS group were referred to the cardiac rehabilitation programme (42.9\% vs $75.9 \%)$ or had cardiology follow-up arranged following discharge from the hospital (73.9\% vs $87.1 \%)$.

\section{Clinical outcomes and predictors of mortality}

In the MINAP cohort, the COVID-19 ACS group had higher in-hospital (24.2\% vs 5.1\%) and 30-day mortality rates (41.9\% vs $7.2 \%$ ) compared with the non COVID-19 ACS cohort. After adjustment for baseline differences in demographics, presenting characteristics, comorbidities and pharmacology, the hierarchical multi-level logistic regression model showed a significantly higher risk of in-hospital (adjusted odds ratio 3.27 95\%CI 2.41-4.42) and 30-day mortality (adjusted odd ratio 6.53 95\%CI 5.12-8.36) in the COVID-19 ACS patients 
medRxiv preprint doi: https://doi.org/10.1101/2020.08.20.20175091.this version posted August 22, 2020. The copyright holder for this preprint (which was not certified by peer review) is the author/funder, who has granted medRxiv a license to display the preprint in perpetuity.

All rights reserved. No reuse allowed without permission.

compared with non COVID-19 ACS patients (Figure 2). In the subgroup analysis stratified according to type of ACS, although short term mortality was similar between the NSTEMI and STEMI groups, the NSTEMI group had higher mortality rates (adjusted odds ratio 8.45 95\%CI 6.03-11.83) at 30-days. Similar, higher mortality rates were observed in COVID-19 ACS patients undergoing PCI compared with non COVID-19 ACS patients undergoing PCI. The multilevel regression model showed that increasing age per year, severe LVSD, inhospital cardiac arrest, peak troponin concentration levels, renal dysfunction and use of $\mathrm{ACE} / \mathrm{ARB}$ on discharge were strong independent risk factors for 30-day mortality in the COVID-19 ACS group (Figure 3).

\section{Discussion}

This multisource, national report of contemporary data from all ACS related hospitalizations in England during the COVID-19 period provides detailed information about the risk profile, clinical care and outcomes of ACS patients with COVID-19 infection. Specifically, COVID19 ACS group had over 6-fold increase in mortality within 30 days compared with non COVID-19 ACS and were less frequently prescribed appropriate secondary prevention medications. They were older, more likely to be of BAME origin, had more comorbid features and exhibited high risk presenting characteristics such as higher Killip class, troponin concentrations, creatinine and evidence of LV systolic dysfunction.

A significant knowledge gap exists in the literature about incidence and profile of ACS patients with concomitant COVID-19 diagnosis, and their associated clinical outcomes. We report that COVID-19 infection in patients presenting with ACS is prevalent at a low level in a national cohort of patients. The higher prevalence of pulmonary oedema and shock at presentation, together with the higher troponin concentrations levels in the COVID-19 ACS cohort are suggestive of increased myocardial injury in this group corroborating findings 
from China and US cohorts ${ }^{19,20}$. However, contrary to earlier small case series from New York and Italy ${ }^{8,9,21}$, the angiographic characteristics of COVID-19 ACS patients were not different from the non COVID-19 ACS patients, with a very small prevalence of nonobstructive coronary disease and similar procedural success.

Whilst previous studies have reported the incidence on myocardial injury based on cardiac biomarker levels in patients hospitalized with a confirmed COVID-19 diagnosis ${ }^{19,20}$, none reported on management and outcomes of ACS patients with concomitant COVID-19 diagnosis in a national, unselected cohort of suspected type 1 myocardial infarction. The management of ACS patients during the COVID-19 pandemic is based on expert clinical guidance which lacks consensus on the optimal treatment strategies for patients presenting with ACS during the COVID-19 outbreak $^{22-25}$. The Chinese Cardiac Society consensus statement proposed medical management for the majority of patients presenting with non-STelevation myocardial infarction (NSTEMI), and thrombolysis in those presenting with STEMI during the COVID-19 pandemic ${ }^{22}$. In contrast, the North America and Canadian guidelines recommended use of thrombolysis as an alternative to primary PCI for patients with STEMI particularly where PCI services are restricted due to COVID-19 ${ }^{23,25}$. However, a joint statement from British Cardiovascular Society, BCIS and NHS England in the UK recommended that primary PCI should remain the default treatment for all STEMI, except in unusual circumstances ${ }^{26}$. In keeping with this national recommendation, we observed almost negligible use of thrombolysis for STEMI in the UK during the acute phase of the COVID-19 pandemic. By contrast, there were significant differences in the care of COVID-19 ACS patients in that only a third of COVID-19 ACS patients received PCI, they experienced greater delays in reperfusion treatment or an invasive strategy and had a significantly lower uptake of secondary prevention medications on discharge. Given that COVID-19 ACS patients presented with more complex, high risk features, there is an urgent need to develop 
effective treatment pathways to align their care with guideline recommendations ${ }^{27,28}$. For patients hospitalized with suspected ACS, especially with elevated cardiac troponin minor ECG changes, an immediate COVID-19 testing should be advocated in the current climate.

In the outcomes analysis, COVID-19 ACS patients had a poor prognosis compared with the non COVID-19 ACS patients. One of four patients died in hospital with an over sixfold higher 30-day mortality in the overall cohort as well as those undergoing PCI. Although we didn't have information regarding the presenting COVID-19 symptoms or respiratory complications in this cohort, we noted significantly higher levels of peak troponin, creatinine, a lower presenting blood pressure and tachycardia in this cohort. Troponin elevation three times the upper reference limit is known to be associated with worse in-hospital outcomes in COVID-19 patients ${ }^{19,20}$. It remains unclear whether the rise in cardiac biomarkers is related to viral myocarditis ${ }^{5,6}$ or plaque rupture secondary to virus-induced inflammatory response $\mathrm{e}^{29-}$ ${ }^{31}$ or a type 1 AMI. In this cohort of suspected type 1 myocardial infarction, there was a low prevalence of non-obstructive coronary disease and the angiographic characteristics and procedural management of the COVID-19 ACS were similar to the non COVID-19 ACS group. We observed higher rates of COVID19 infection and subsequent 30-day morality in NSTEMI compared with STEMI. Patients presenting with NSTEMI are generally older, more comorbid and less likely to present early during the COVID-19 pandemic which in conjunction with increased infection rates may be responsible for their poor outcomes.

The COVID-19 ACS cohort were also less frequently prescribed low molecular weight or unfractionated heparin and statins. Patients with acute COVID-19 are known to be at increased risk of thromboembolic complications and are therefore likely to benefit from appropriate anticoagulation to reduce thrombus burden and statins to stabilize plaque. In the risk factor analysis, elevated creatinine, peak troponin, heart rate, left ventricular systolic dysfunction and use of ACE inhibitor or ARBs were strong independent risk factors for 30- 
day mortality in this report. Although recent data have negated earlier concerns of an increased risk of adverse outcomes in COVID-19 patients with use of ACE inhibitors or ARBs, further research is required to establish the role of these medications in patients presenting with COVID-19 $\mathrm{ACS}^{32,33}$. Patients hospitalized with ACS and concomitant COVID-19 infection may also be focus of specific anti-viral drug trials or immunosuppression therapy to establish the benefit of these therapies in this high risk cohort $^{7}$.

The interrogation of multisource, multihospital live data from England has given insight in to the presenting characteristics, risk profile, treatment strategies and 30-day mortality in an unselected cohort of patients hospitalized with COVID-19 ACS. However, there are some study limitations which must be kept in mind whilst interpreting these findings. First, the COVID-19 diagnosis was based on the ICD-10 codes and so it is unclear whether the diagnosis at the hospital was made on clinical grounds or using a formal polymerase chain reaction (PCR) test, and the timing of the tests leading to the diagnosis is unclear. Moreover, other suspected ACS patients were not routinely tested at the start of the pandemic and we cannot say how many might have been carrying the virus, although the lack of a COVID-19 code suggests they did not have a clinical syndrome related to the virus. Second, information around COVID-19 symptoms, their duration and other organ involvement is not captured in the datasets used in this analysis, and hence it difficult to ascertain whether patients had COVID-19 symptoms followed by an ACS or vice versa, and whether COVID-19 infection occurred in the hospital or the community. Third, whilst the MINAP registry is the UK national ACS registry for suspected type1 AMI, we cannot rule out misclassification bias from misdiagnosis of myocarditis or type 2 AMI, although only a small proportion of cases that underwent angiography had non-obstructive coronary artery disease. 


\section{Conclusion}

COVID-19 infection was present in $4 \%$ of patients hospitalized with a suspected ACS in England during the study period. It was associated with worst outcomes independent of the type of ACS, however higher 30-day mortality was observed in NSTEMI group compared with STEMI group. Elderly, comorbid and BAME patients with underlying cardiovascular disease are more likely to acquire COVID-19 infection and often present with unfavourable presenting characteristics. These findings highlight the need to develop strategies for an efficient and equitable care for COVID ACS patients.

\section{Acknowledgments}

The authors acknowledge Chris Roebuck, Tom Denwood, Tony Burton and Courtney Stephenson and data support staff at NHS Digital for providing and creating the secure environment for data hosting and for analytical support, and Anil Gunesh and Julian Hains from the National Institute of Cardiovascular Outcomes Research for data transfer into the secure environment. This work uses data provided by patients and collected by the NHS as part of their care and support and authors would like to thank all for their contributions. 
Table 1: Baseline characteristics COVID19 ACS compared to non COVID19 ACS patients in the MINAP registry

\begin{tabular}{|c|c|c|c|}
\hline \multirow[b]{2}{*}{ Variables } & \multicolumn{3}{|c|}{ COVID19 ACS } \\
\hline & $\begin{array}{c}\text { Non COVID19 ACS } \\
\mathrm{N}=12,441\end{array}$ & $\mathrm{~N}=517$ & $\mathrm{P}$ value \\
\hline Age, years mean $(\mathrm{SD})$ & $67.0(13.3)$ & $72.8(13.9)$ & $<0.001$ \\
\hline Male $(\%)$ & 8587 (69.1\%) & $352(68.1 \%)$ & 0.63 \\
\hline BMI mean (SD) & $28.2(5.5)$ & $26.9(5.6)$ & $<0.001$ \\
\hline Ethnicity & & & $<0.001$ \\
\hline Whites & $9290(87.2 \%)$ & $360(79.8 \%)$ & \\
\hline BAME & $1359(12.8 \%)$ & $91(20.2 \%)$ & \\
\hline \multicolumn{4}{|l|}{ Presenting Characteristics } \\
\hline Heart rate, bpm, mean (SD) & $79.9(19.9)$ & $86.7(22.9)$ & $<0.001$ \\
\hline Systolic blood pressure, mean (SD) & $140.7(27.5)$ & $134.7(29.9)$ & $<0.001$ \\
\hline Cardiac arrest & & & $<0.001$ \\
\hline Pre hospital cardiac arrest & $434(3.7 \%)$ & $17(3.5 \%)$ & \\
\hline In- hospital cardiac arrest & $349(3.0 \%)$ & $31(6.3 \%)$ & \\
\hline Clinical syndrome & & & 0.02 \\
\hline STEMI & $4403(38.0 \%)$ & $153(33.0 \%)$ & \\
\hline NSTEMI & $7176(62.0 \%)$ & $311(67.0 \%)$ & \\
\hline \multicolumn{4}{|l|}{ Peak troponin levels (median, $I Q R$ ) } \\
\hline Troponin $\mathrm{T}$ & $99(13-685)$ & $380(63.7-20.45)$ & 0.002 \\
\hline Troponin I & $399(48.9-4036)$ & $431(109-3396)$ & 0.83 \\
\hline Highly sensitive troponin $\mathrm{T}$ & $231(55-1149)$ & $245(41-946)$ & 0.61 \\
\hline Highly sensitive troponin I & $482(53-4193)$ & $853(144-4374)$ & 0.04 \\
\hline Creatinine, mean (SD) & $94.9(62.4)$ & $134.2(115.2)$ & $<0.001$ \\
\hline Kilip Class & & & $<0.001$ \\
\hline No heart failure & $9114(84.0 \%)$ & $280(60.0 \%)$ & \\
\hline Basal crepitation & $952(8.8 \%)$ & $100(21.4 \%)$ & \\
\hline Pulmonary oedema & $368(3.4 \%)$ & $42(9.0 \%)$ & \\
\hline Cardiogenic shock & $421(3.9 \%)$ & $45(9.6 \%)$ & \\
\hline LV systolic function & & & $<0.001$ \\
\hline
\end{tabular}


medRxiv preprint doi: https://doi.org/10.1101/2020.08.20.20175091.this version posted August 22, 2020. The copyright holder for this preprint (which was not certified by peer review) is the author/funder, who has granted medRxiv a license to display the preprint in perpetuity.

All rights reserved. No reuse allowed without permission.

Good

Moderate

Poor

Not assessed

\section{Comorbidities}

Percutaneous coronary intervention

Coronary artery bypass graft

Heart failure

Hypercholesterolemia

Angina

Cerebrovascular disease

Myocardial infarction

Peripheral vascular disease

Chronic kidney disease

Diabetes

Not diabetic

Diet controlled

Oral medications

Insulin therapy

Hypertension

Smoking status

Never smoked

Previous smoker

Current smoker

Asthma / COPD

Family history of CHD

In-hospital Pharmacology

LMWH/UFH

Warfarin

Loop Diuretic

Glycoprotein IIbIIIa inhibitor use

$\begin{array}{cc}4593(46.1 \%) & 132(30.3 \%) \\ 2665(26.8 \%) & 110(25.3 \%) \\ 838(8.4 \%) & 59(13.6 \%) \\ 1861(18.7 \%) & 134(30.8 \%)\end{array}$

2077 (19.5\%)

$746(7.1 \%)$

1419 (13.4\%)

4439 (40.8\%)

2004 (19.2\%)

848 (8.0\%)

2747 (25.5\%)

$560(5.3 \%)$

$884(8.4 \%)$

8547 (73.9\%)

513 (4.4\%)

1635 (14.1\%)

868 (7.5\%)

6474 (58.3\%)

$3965(37.6 \%)$

3584 (34.0\%)

3003 (28.5\%)

1753 (16.8\%)

$2430(27.8 \%)$

6261 (72.7\%)

$268(3.1 \%)$

1801 (21.1\%)

1147 (12.5\%)
$71(15.1 \%)$

39 (8.3\%)

112 (23.7\%)

183 (39.0\%)

$83(17.8 \%)$

74 (15.7\%)

$136(28.6 \%)$

31 (6.6\%)

$112(23.7 \%)$

$<0.001$

$<0.001$

298 (60.3\%)

31 (6.3\%)

98 (19.8\%)

67 (13.6\%)

335 (69.4\%)

$<0.001$

$<0.001$

152 (43.1\%)

150 (42.5\%)

$51(14.4 \%)$

$95(20.3 \%) \quad 0.04$

$51(14.4 \%) \quad<0.001$

Discharge Pharmacology

$<0.001$

0.11

$166(45.0 \%) \quad<0.001$

$36(9.1 \%) \quad 0.04$ 
medRxiv preprint doi: https://doi.org/10.1101/2020.08.20.20175091.this version posted August 22, 2020. The copyright holder for this preprint (which was not certified by peer review) is the author/funder, who has granted medRxiv a license to display the preprint in perpetuity.

All rights reserved. No reuse allowed without permission.

Any P2Y12 Inhibitor

Dual Antiplatelet medications

Statin

ACEi / ARB
$10552(92.8 \%)$

$9874(88.0 \%)$

$9892(95.1 \%)$

9195 (88.6\%)
$387(84.1 \%) \quad<0.001$

$345(76.3 \%) \quad<0.001$

$343(89.1 \%) \quad<0.001$

$304(80.4 \%) \quad<0.001$

Processes of Care and Clinical outcomes

Seen by cardiologist

$11436(97.2 \%)$

$445(90.4 \%)$

$<0.001$

Percutaneous coronary intervention

$6708(53.9 \%)$

$156(30.2 \%)$

$<0.001$

Why no PCI

$<0.002$

Angiographically normal coronaries

$319(4.8 \%)$

$4(1.7 \%)$

PCI inappropriate

$356(5.4 \%)$

$22(5.8 \%)$

Surgical disease

$135(2.0 \%)$

$4(1.8 \%)$

Coronary angiography in NSTEMI

$5,259(88.2 \%)$

$107(68.5 \%)$

$<0.001$

PCI in NSTEMI

$3,299(46.0 \%)$

$69(22.2 \%)$

$<0.001$

Time to reperfusion for STEMI, hours median IQR

$0.76(0.50-1.27) \quad 0.98(0.65-1.52) \quad<0.001$

Call for help, hour median (IQR)

$1.45(0.47-5.3)$

$2.0(0.40-6.8)$

0.26

Time to coronary angiography, hour median (IQR)

$33.7(14.4-128.8) \quad 38.1(18.3-70.8) \quad<0.01$

Referral for cardiac Rehabilitation

$8204(75.9 \%)$

$192(42.9 \%) \quad<0.001$

Cardiology follow up

$8018(87.1 \%)$

$221(73.9 \%)$

$<0.001$

In-hospital mortality

$592(5.1 \%)$

$114(24.2 \%) \quad<0.001$

30-day mortality

$843(7.2 \%)$

207 (41.9\%)

$<0.001$

Table 2: Clinical characteristics of COVID19 ACS compared to non COVID19 ACS patients undergoing PCI in the BCIS registry

\begin{tabular}{llll}
\hline Variables & \multicolumn{1}{c}{$\begin{array}{c}\text { Non COVID19 ACS } \\
\text { N=6708 }\end{array}$} & $\begin{array}{c}\text { COVID19 ACS } \\
\text { N=156 }\end{array}$ & P value \\
& & & \\
\hline Age, years mean (SD) & $64.4(12.0)$ & $65.3(12.5)$ & 0.38 \\
Male (\%) & $5019(74.9 \%)$ & $118(75.6 \%)$ & 0.84 \\
BMI mean (SD) & $28.5(5.2)$ & $27.9(4.8)$ & 0.17 \\
Ethnicity & & & $<0.001$
\end{tabular}


Whites

BAME

Presenting Characteristics

Heart rate, bpm, mean (SD)

Systolic blood pressure, mean (SD)

Cardiac arrest

Pre hospital cardiac arrest

In- hospital cardiac arrest

Clinical syndrome

STEMI

NSTEMI

Creatinine, mean (SD)

Kilip Class

No heart failure

Basal crepitation

Pulmonary oedema

Cardiogenic shock

LV systolic function

Good

Moderate

Poor

Not assessed

\section{Comorbidities}

Percutaneous coronary intervention $1265(22.0 \%)$

Coronary artery bypass graft

$303(5.4 \%)$

Heart failure

$542(9.6 \%)$

Hypercholesterolemia

Angina

Cerebrovascular disease

Myocardial infarction

Peripheral vascular disease

Chronic kidney disease

Diabetes
5045 (85.5\%)

$853(14.5 \%)$
$78.1(18.4)$

$140.3(27.1)$

274 (4.3\%)

$179(2.8 \%)$

3394 (50.7\%)

3299 (49.3\%)

$89.2(53.0)$

5224 (87.8\%)

$336(5.6 \%)$

$136(2.3 \%)$

$251(4.2 \%)$

$2750(50.8 \%)$

1704 (31.5\%)

$421(7.8 \%)$

$539(10.0 \%)$
2949 (49.5\%)

$812(14.6 \%)$

$361(6.4 \%)$

$1412(24.4 \%)$

$282(5.0 \%)$

$274(4.9 \%)$

$104(72.7 \%)$

$39(27.3 \%)$

$83.8(20.9)$

$<0.001$

$137.1(31.5)$

0.18

$<0.001$

$9(6.2 \%)$

14 (9.7\%)

87 (55.8\%)

69 (44.2\%)

114.6 (105.2) $<0.001$ $<0.001$

95 (66.0\%)

$18(12.5 \%)$

14 (9.7\%)

17 (11.8\%)

0.21

58 (43.6\%)

50 (37.6\%)

14 (10.5\%)

$11(8.3 \%)$
31 (21.8\%)

11 (7.9\%)

20 (14.6\%)

72 (51.1\%)

14 (10.4\%)

15 (10.8\%)

42 (29.8\%)

14 (10.1\%)

$22(16.1 \%)$
0.96

0.22

0.05

0.72

0.17

0.03

0.14

0.007

$<0.001$ 


\begin{tabular}{|c|c|c|c|}
\hline Not diabetic & $4716(75.5 \%)$ & $91(60.7 \%)$ & \\
\hline Diet controlled & $274(4.4 \%)$ & $6(4.0 \%)$ & \\
\hline Oral medications & $872(14.0 \%)$ & $33(22.0 \%)$ & \\
\hline Insulin therapy & $384(6.1 \%)$ & $20(13.3 \%)$ & \\
\hline Hypertension & $3678(60.2 \%)$ & $104(71.7 \%)$ & 0.005 \\
\hline Smoking status & & & 0.02 \\
\hline Never smoked & $2462(38.3 \%)$ & $66(46.2 \%)$ & \\
\hline Previous smoker & $2040(31.7 \%)$ & 49 (34.3\%) & \\
\hline Current smoker & $1934(30.0 \%)$ & $28(19.6 \%)$ & \\
\hline Asthma / COPD & $765(13.7 \%)$ & $18(13.3 \%)$ & 0.90 \\
\hline Family history of CHD & $1542(31.8 \%)$ & $28(26.2 \%)$ & 0.21 \\
\hline \multicolumn{4}{|l|}{ In-hospital Pharmacology } \\
\hline Low molecular weight heparin & $1867(43.2 \%)$ & $39(42.4 \%)$ & 0.88 \\
\hline Unfractionated heparin & $2092(47.2 \%)$ & $34(36.2 \%)$ & 0.03 \\
\hline Warfarin & $98(2.2 \%)$ & $5(5.4 \%)$ & 0.04 \\
\hline Loop Diuretic & $676(15.6 \%)$ & $31(33.7 \%)$ & $<0.001$ \\
\hline Glycoprotein IIbIIIa inhibitor use & $1015(20.7 \%)$ & $32(27.6 \%)$ & 0.07 \\
\hline \multicolumn{4}{|l|}{ Discharge Pharmacology } \\
\hline Aspirin & $6226(98.2 \%)$ & $138(97.9 \%)$ & 0.76 \\
\hline Any P2Y12 Inhibitor & $6013(97.3 \%)$ & $121(92.4 \%)$ & $<0.001$ \\
\hline Dual Antiplatelet medications & $5827(95.6 \%)$ & $116(89.9 \%)$ & 0.002 \\
\hline Statin & $5645(97.6 \%)$ & $107(95.5 \%)$ & 0.17 \\
\hline $\mathrm{ACEi} / \mathrm{ARB}$ & $5391(93.1 \%)$ & $110(94.0 \%)$ & 0.70 \\
\hline \multicolumn{4}{|l|}{$\begin{array}{l}\text { Processes of Care and Clinical } \\
\text { outcomes }\end{array}$} \\
\hline Referral for cardiac Rehabilitation & 5068 (86.3\%) & $84(64.1 \%)$ & $<0.001$ \\
\hline Cardiology follow up & $4662(93.3 \%)$ & $87(89.7 \%)$ & 0.16 \\
\hline In-hospital mortality & $180(2.8 \%)$ & $19(14.0 \%)$ & $<0.001$ \\
\hline 30-day mortality & $260(4.1 \%)$ & $44(30.8 \%)$ & $<0.001$ \\
\hline
\end{tabular}

Table 3: Angiographic characteristics and procedural outcomes of COVID19 ACS patients compared to non COVID19 ACS patients undergoing PCI in the BCIS registry 


\begin{tabular}{|c|c|c|c|}
\hline Variables & $\begin{array}{l}\text { Non COVID19 AMI } \\
\qquad \mathrm{N}=6708\end{array}$ & $\begin{array}{l}\text { COVID19 AMI } \\
\qquad \mathrm{N}=157\end{array}$ & P value* \\
\hline \multicolumn{4}{|l|}{ Procedural characteristics } \\
\hline Arterial blood gas PH & $7.2(0.2)$ & $7.3(0.1)$ & \\
\hline Base excess & $-2.6(6.25)$ & $-2.55(6.9)$ & $<0.001$ \\
\hline Glasgow come scale & & & 0.007 \\
\hline $\mathrm{GCS}<8$ & $132(27.8 \%)$ & $2(25.0 \%)$ & \\
\hline $\mathrm{GCS} \geq 8$ & $342(72.2 \%)$ & $6(75.0 \%)$ & \\
\hline Mechanical ventilation & $113(16.4 \%)$ & $5(35.7 \%)$ & 0.05 \\
\hline Lesion attempted & & & 0.35 \\
\hline 0 & $186(2.8 \%)$ & $4(2.6 \%)$ & \\
\hline 1 & $4644(70.2 \%)$ & $101(65.6 \%)$ & \\
\hline 2 & $1331(20.1 \%)$ & $33(21.4 \%)$ & \\
\hline 3 or more & $455(6.9 \%)$ & $16(10.4 \%)$ & \\
\hline \multicolumn{4}{|l|}{ Vessel attempted } \\
\hline Grafts & $138(2.0 \%)$ & $5(3.2 \%)$ & 0.32 \\
\hline LMS & 285 (4.2\%) & $13(8.3 \%)$ & 0.01 \\
\hline RCA & 2338 (34.8\%) & $54(34.6 \%)$ & 0.95 \\
\hline LAD & $3271(48.8 \%)$ & $83(53.2 \%)$ & 0.27 \\
\hline LCX & $1601(23.9 \%)$ & $33(21.2 \%)$ & 0.43 \\
\hline Multi-vessel PCI & $992(14.8 \%)$ & $31(19.9 \%)$ & 0.07 \\
\hline Number of stents & & & 0.12 \\
\hline 0 & $886(13.5 \%)$ & $19(12.3 \%)$ & \\
\hline 1 & $3462(52.6 \%)$ & $77(50.0 \%)$ & \\
\hline 2 & $1527(23.2 \%)$ & $32(20.8 \%)$ & \\
\hline 3 or more & $711(10.8 \%)$ & $26(16.9 \%)$ & \\
\hline Inotropic support & $128(2.0 \%)$ & $7(4.8 \%)$ & 0.01 \\
\hline Intra-aortic balloon pump & $48(0.8 \%)$ & $4(2.8 \%)$ & 0.006 \\
\hline TIMI flow post PCI & & & 0.31 \\
\hline 0 & $146(3.2 \%)$ & $1(1.0 \%)$ & \\
\hline 1 & $41(0.9 \%)$ & $0(0.0 \%)$ & \\
\hline 2 & $175(3.8 \%)$ & $6(6.0 \%)$ & \\
\hline
\end{tabular}


medRxiv preprint doi: https://doi.org/10.1101/2020.08.20.20175091.this version posted August 22, 2020. The copyright holder for this preprint (which was not certified by peer review) is the author/funder, who has granted medRxiv a license to display the preprint in perpetuity. All rights reserved. No reuse allowed without permission.

\begin{tabular}{lccc}
\hline 3 & $4209(92.1 \%)$ & $93(93.0 \%)$ & \\
IVUS use & $639(11.9 \%)$ & $24(16.9 \%)$ & 0.07 \\
OCT use & $191(3.9 \%)$ & $1(0.8 \%)$ & 0.08 \\
FFR/iFR use & $419(8.2 \%)$ & $2(1.7 \%)$ & 0.01 \\
Procedural outcomes & & & \\
MACCE & $201(3.1 \%)$ & $14(9.4 \%)$ & $<0.001$ \\
In-hospital death & $180(2.8 \%)$ & $19(14.0 \%)$ & $<0.001$ \\
30 day mortality & $260(4.1 \%)$ & $44(30.8 \%)$ & $<0.001$
\end{tabular}

Figure 1: Daily cases of COVID19 ACS hospitalized during the study period

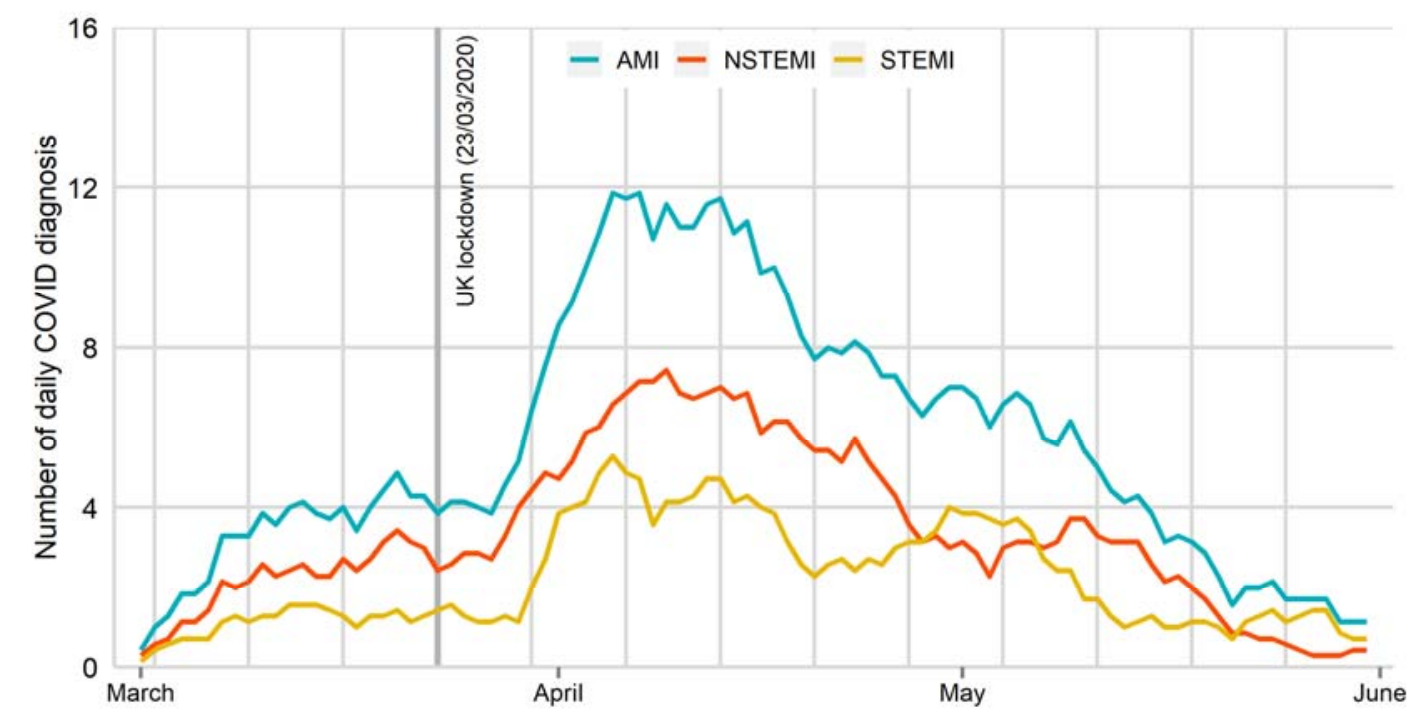


Figure 2: In hospital outcomes and 30-day mortality of COVID19 ACS patient compared to non COVID19 ACS patients

\section{Overall cohort}

\section{In-hospital mortality}

Unadjusted

30-day mortality

Unadjusted

Adjusted

\section{ACS type}

STEMI

In-hospital mortality

Unadjusted

Adjusted

\section{0-day mortality}

Unadjusted

Adjusted

\section{NSTEMI}

In-hospital mortality

Unadjusted

Adjusted

30-day mortality

Unadjusted

Adjusted

\section{$\mathrm{PCl}$ cohort}

\section{In-hospital mortality}

Unadjusted

Adjusted

30-day mortality

Unadjusted

Adjusted
OR $(95 \% \mathrm{Cl})$

$5.66(4.52-7.08)$

$3.27(2.41-4.42)$

$9.18(7.06-11.01)$

$6.53(5.10-8.36)$

$4.23(2.81-6.35)$

3.30 (1.85-5.89)

$5.66(3.92-8.15)$

4.68 (2.88-7.59)

6.73 (4.83-9.37)

$3.56(2.23-5.67)$

$12.64(9.72-16.44)$

$8.45(6.03-11.83)$

$5.02(3.04-8.31)$

$4.39(2.26-8.51)$

$9.74(6.72-14.10)$

$9.64(5.96-15.61)$

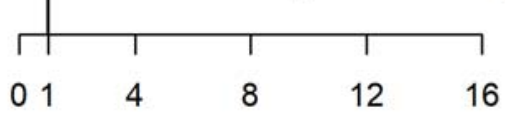

Odds ratio 
medRxiv preprint doi: https://doi.org/10.1101/2020.08.20.20175091.this version posted August 22, 2020. The copyright holder for this preprint (which was not certified by peer review) is the author/funder, who has granted medRxiv a license to display the preprint in perpetuity. All rights reserved. No reuse allowed without permission.

Figure 3: Independent predictors of 30-day mortality in COVID positive AMI patients

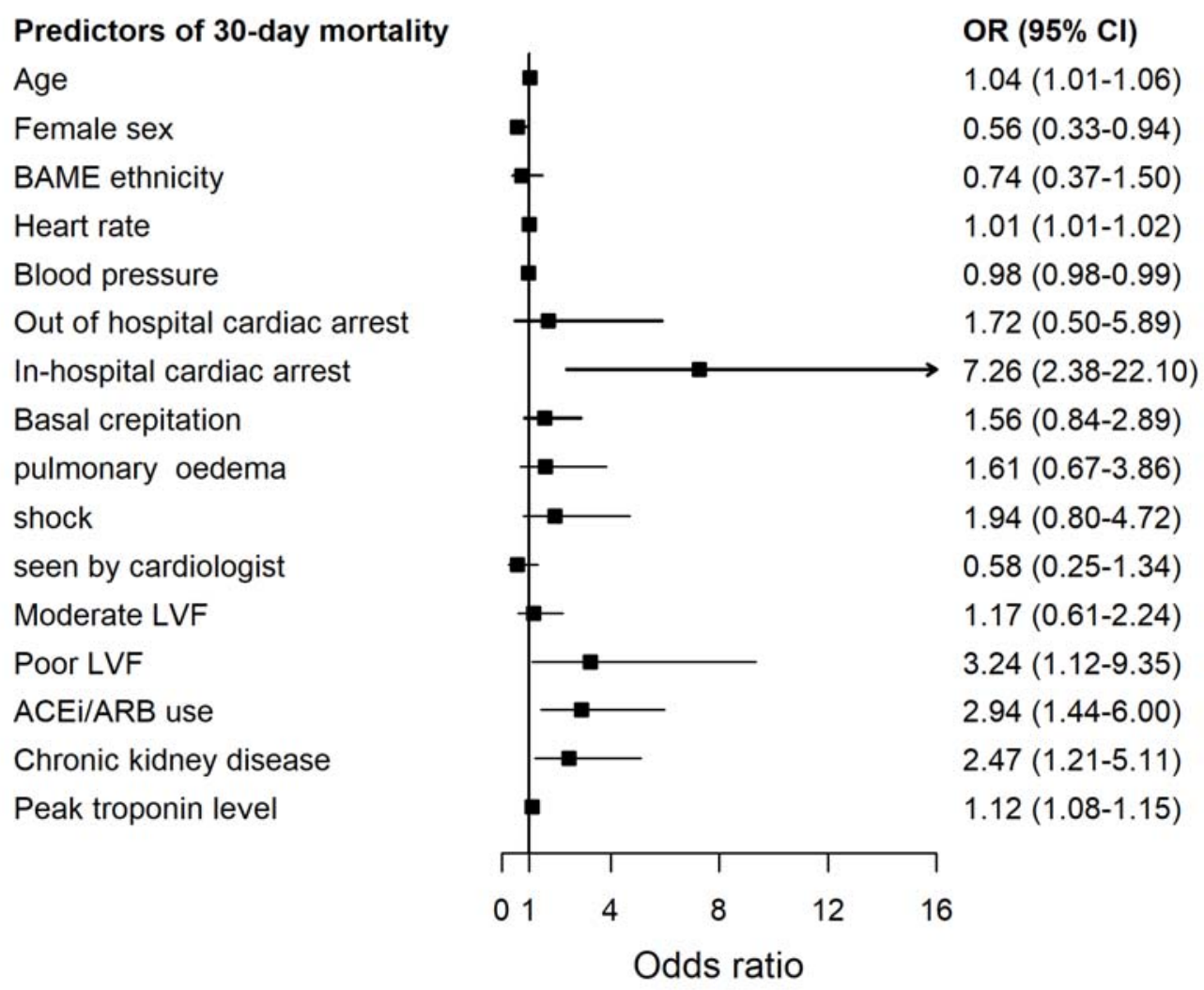




\section{REFERENCES}

1. CSSE J. Coronavirus COVID-19 Global Cases by the Center for Systems Science and Engineering (CSSE) at Johns Hopkins University (JHU). 2020-03-

15].https://gisanddata.maps.arcgis.com/apps/opsdashboard/index.html\#/bda7594740fd40 $299423467 b 48 e 9 e c f 6.2020$.

2. Gulati A, Pomeranz C, Qamar Z, et al. A Comprehensive Review of Manifestations of Novel Coronaviruses in the Context of Deadly COVID-19 Global Pandemic. Am J Med Sci. 2020;360(1):5-34. doi: S0002-9629(20)30179-8 [pii].

3. Gupta A, Madhavan MV, Sehgal K, et al. Extrapulmonary manifestations of COVID-19. Nat Med. 2020;26(7):1017-1032. doi: 10.1038/s41591-020-0968-3 [doi].

4. Montone RA, Iannaccone G, Meucci MC, Gurgoglione F, Niccoli G. Myocardial and Microvascular Injury Due to Coronavirus Disease 2019. Eur Cardiol. 2020;15:e52. doi: 10.15420/ecr.2020.22 [doi].

5. Zeng JH, Liu YX, Yuan J, et al. First case of COVID-19 complicated with fulminant myocarditis: a case report and insights. Infection. 2020. doi: 10.1007/s15010-020-01424-5 [doi].

6. Inciardi RM, Lupi L, Zaccone G, et al. Cardiac Involvement in a Patient With Coronavirus Disease 2019 (COVID-19). JAMA cardiology. 2020;5(7):819. doi:

10.1001/jamacardio.2020.1096.

7. Bonow RO, Fonarow GC, O'Gara PT, Yancy CW. Association of Coronavirus Disease 2019 (COVID-19) With Myocardial Injury and Mortality. JAMA Cardiol. 2020. doi:

10.1001/jamacardio.2020.1105 [doi]. 
medRxiv preprint doi: https://doi.org/10.1101/2020.08.20.20175091.this version posted August 22, 2020. The copyright holder for this preprint (which was not certified by peer review) is the author/funder, who has granted medRxiv a license to display the preprint in perpetuity.

All rights reserved. No reuse allowed without permission.

8. Bangalore S, Sharma A, Slotwiner A, et al. ST-Segment Elevation in Patients with Covid19 - A Case Series. N Engl J Med. 2020;382(25):2478-2480. doi: 10.1056/NEJMc2009020 [doi].

9. Stefanini GG, Montorfano M, Trabattoni D, et al. ST-Elevation Myocardial Infarction in Patients With COVID-19: Clinical and Angiographic Outcomes. Circulation. 2020;141(25):2113-2116. doi: 10.1161/CIRCULATIONAHA.120.047525 [doi].

10. Williams JG, Mann RY. Hospital episode statistics: time for clinicians to get involved?. Clinical Medicine. 2002;2(1):34.

11. Rashid M, Ludman PF, Mamas MA. British Cardiovascular Intervention Society registry framework: a quality improvement initiative on behalf of the National Institute of Cardiovascular Outcomes Research (NICOR). Eur Heart J Qual Care Clin Outcomes. 2019;5(4):292-297. doi: 10.1093/ehjqcco/qcz023 [doi].

12. Wilkinson C, Weston C, Timmis A, Quinn T, Keys A, Gale CP. The Myocardial Ischaemia National Audit Project (MINAP). Eur Heart J Qual Care Clin Outcomes. 2020;6(1):19-22. doi: 10.1093/ehjqcco/qcz052 [doi].

13. Noman A, Balasubramaniam K, Alhous MHA, et al. Mortality after percutaneous coronary revascularization: Prior cardiovascular risk factor control and improved outcomes in patients with diabetes mellitus. Catheter Cardiovasc Interv. 2017;89(7):1195-1204. doi: 10.1002/ccd.26882 [doi].

14. Taxiarchi P, Kontopantelis E, Martin GP, et al. Same-day discharge after elective percutaneous coronary intervention: insights from the British Cardiovascular Intervention Society. JACC: Cardiovascular Interventions. 2019;12(15):1479-1494. 
medRxiv preprint doi: https://doi.org/10.1101/2020.08.20.20175091.this version posted August 22, 2020. The copyright holder for this preprint (which was not certified by peer review) is the author/funder, who has granted medRxiv a license to display the preprint in perpetuity.

All rights reserved. No reuse allowed without permission.

15. Rashid M, Curzen N, Kinnaird T, et al. Baseline risk, timing of invasive strategy and guideline compliance in NSTEMI: Nationwide analysis from MINAP. Int J Cardiol. 2020;301:7-13. doi: S0167-5273(19)34933-2 [pii].

16. Rashid M, Kontopantelis E, Kinnaird T, et al. Association Between Hospital Cardiac Catheter Laboratory Status, Use of an Invasive Strategy, and Outcomes After NSTEMI. Can J Cardiol. 2019. doi: S0828-282X(19)31344-3 [pii].

17. Rubin DB. Multiple Imputation for Nonresponse in Surveys 1987 Wiley New York. 1987.

18. Rubin DB. Multiple imputation after 18 years. Journal of the American statistical Association. 1996;91(434):473-489.

19. Shi S, Qin M, Shen B, et al. Association of Cardiac Injury With Mortality in Hospitalized Patients With COVID-19 in Wuhan, China. JAMA Cardiol. 2020. doi:

10.1001/jamacardio.2020.0950 [doi].

20. Lala A, Johnson KW, Januzzi JL, et al. Prevalence and Impact of Myocardial Injury in Patients Hospitalized With COVID-19 Infection. J Am Coll Cardiol. 2020;76(5):533-546. doi: S0735-1097(20)35552-2 [pii].

21. Hamadeh A, Aldujeli A, Briedis K, et al. Characteristics and Outcomes in Patients Presenting With COVID-19 and ST-Segment Elevation Myocardial Infarction. Am J Cardiol. 2020. doi: S0002-9149(20)30641-X [pii].

22. Han Y, Zeng H, Jiang H, et al. CSC Expert Consensus on Principles of Clinical Management of Patients With Severe Emergent Cardiovascular Diseases During the COVID- 
19 Epidemic. Circulation. 2020;141(20):e810-e816. doi:

10.1161/CIRCULATIONAHA.120.047011 [doi].

23. Wood DA, Sathananthan J, Gin K, et al. Precautions and Procedures for Coronary and Structural Cardiac Interventions During the COVID-19 Pandemic: Guidance from Canadian Association of Interventional Cardiology. Can J Cardiol. 2020;36(5):780-783. doi: S0828$282 X(20) 30300-7$ [pii].

24. Welt FG, Shah PB, Aronow HD, et al. Catheterization Laboratory Considerations During the Coronavirus (COVID-19) Pandemic: From the ACC's Interventional Council and SCAI. J Am Coll Cardiol. 2020;75(18):2372-2375.

25. Mahmud E, Dauerman HL, Welt FG, et al. Management of acute myocardial infarction during the COVID-19 pandemic. J Am Coll Cardiol. 2020.

26. England N, Improvement N. Clinical guide for the management of cardiology patients during the coronavirus pandemic.

27. Roffi M, Patrono C, Collet JP, et al. 2015 ESC Guidelines for the management of acute coronary syndromes in patients presenting without persistent ST-segment elevation: Task Force for the Management of Acute Coronary Syndromes in Patients Presenting without Persistent ST-Segment Elevation of the European Society of Cardiology (ESC). Eur Heart J. 2016;37(3):267-315. doi: 10.1093/eurheartj/ehv320 [doi].

28. Amsterdam EA, Wenger NK, Brindis RG, et al. 2014 AHA/ACC Guideline for the Management of Patients with Non-ST-Elevation Acute Coronary Syndromes: a report of the American College of Cardiology/American Heart Association Task Force on Practice Guidelines. J Am Coll Cardiol. 2014;64(24):139. doi: 10.1016/j.jacc.2014.09.017 [doi]. 
29. Cappuccio FP, Siani A. Covid-19 and cardiovascular risk: Susceptibility to infection to SARS-CoV-2, severity and prognosis of Covid-19 and blockade of the renin-angiotensinaldosterone system. An evidence-based viewpoint. Nutr Metab Cardiovasc Dis.

2020;30(8):1227-1235. doi: S0939-4753(20)30206-4 [pii].

30. Marchetti M. COVID-19-driven endothelial damage: complement, HIF-1, and ABL2 are potential pathways of damage and targets for cure. Ann Hematol. 2020;99(8):1701-1707. doi: 10.1007/s00277-020-04138-8 [doi].

31. Tahir F, Bin Arif T, Ahmed J, Malik F, Khalid M. Cardiac Manifestations of Coronavirus Disease 2019 (COVID-19): A Comprehensive Review. Cureus. 2020;12(5):e8021. doi: 10.7759/cureus.8021 [doi].

32. Mancia G, Rea F, Ludergnani M, Apolone G, Corrao G. Renin-Angiotensin-Aldosterone System Blockers and the Risk of Covid-19. N Engl J Med. 2020;382(25):2431-2440. doi: 10.1056/NEJMoa2006923 [doi].

33. Reynolds HR, Adhikari S, Pulgarin C, et al. Renin-Angiotensin-Aldosterone System Inhibitors and Risk of Covid-19. N Engl J Med. 2020;382(25):2441-2448. doi: 10.1056/NEJMoa2008975 [doi]. 